\title{
The prevalence of emotional distress factors associated with stress among nurses
}

\author{
Univ Assist. Lavinia HOGEA, MD, Assoc. Prof. Laura NUSSBAUM, MD, PhD, \\ Lecturer Cristina Ana BREDICEAN, MD
}

Neuroscience Department, „Victor Babes“ University of Medicine and Pharmacy, Timisoara

\begin{abstract}
The purpose of this study was to determine the incidence of emotional distress associated with stressors among nurses.

70 nurses were selected according to the department in which they work: Hematology, Pediatrics, Cardiology, Intensive Therapy and the Emergency section, ranging from 23 to 58 years, and the average age of 35.3 ani.

For data collection, the following questionnaires were used: Stress Perception Scale and Affective Distraction Scale.

The results obtained show significant differences between the different groups: Hematology, Pediatrics, Cardiology, Intensive Therapy and Emergencies regarding both the perception of stress and emotional distress.

The study may be useful in setting preventive measures and finding ways to combat stress.
\end{abstract}

Keywords: emotional distress, stress, nursing

\section{INTRODUCTION}

Distress is the malady of the modern age, underlying many physical, mental and emotional illnesses, affecting the reason, balance and the human actions, actions that affect those we have been empowered to encourage, support, help, care - in a word, to bless them.

Before entering the battle ring, a good fighter knows his opponent, seeks to find out what his weapons are, how and where he attacks and what are the weaknesses, and then he forms a strategy. Starting from the premise that emotional distress is the enemy of a medical assistant, this study attempts to find out what trigger factors are and how distress both the health of an assistant and his work from a professional point of view (1-4).
Although in the last two decades the emotional distress has been studied in accordance with the rational emotional and behavioral theory and the role of mediators such as irrationality, certain variables of personality: neurosis, lack of control, self-confidence, yet the psychological mediators of emotional distress in the case of nurses remains with many unknowns and therefore the development of effective distress management programs is difficult (5-7).

\section{SUBJECTS AND METHODS}

Within the present process, a number of 70 nurses aged 23-58 years were selected, with an average age of 35.3 years.

\section{Corrresponding author:}

Assoc. Prof. Laura Nussbaum, MD PhD, Neuroscience Department, „Victor Babes“ University of Medicine and Pharmacy, 2 Eftimie Murgu Sqr., Timisoara, Romania; Psychiatry and Neurology Pediatric Clinic, Timisoara, Romania

E-mail: nussbaumlaura@yahoo.com 
The nurses participating in the study were divided into five categories, depending on the department where they are active: Hematology, Pediatrics, Cardiology, Intensive Therapy and Emergency. The research was conducted in 2017 in Timisoara hospitals. The mode of sampling was the non-randomized -pseudo-randomized or the collusion method, the participants giving their written consent to fill out the questionnaires.

In order to achieve the objectives, the following instruments were applied:

- The Perceived Stress Questionnaire, developed by Levenstein et al. (1993), is a relevant tool in determining the level of perceived stress. The score, ranging from 30 to 120 , allows the subject to fall into one of three categories: low stress, moderate stress and intense stress.

- The scale of affective distress is a tool developed to assess the subjective dimension of functional negative emotions, dysfunctional negative emotions and positive emotions. The scale contains 39 items that measure functional and dysfunctional negative emotions in the categories of "worry / anxiety" and "sadness / depression" as well as positive emotions (8).

\section{RESULTS}

In order to obtain the result, the subjects were divided into three categories: nurses with over 10 years of service, nurses with 5-10 years of service and nurses under 5 years of service.

The differences among nurses relative to the length of work in terms of stress level are highlighted in Fig. 1.

In line with Figure 1, nurses who have over 10 years of work experience a present a stress level reduced by $17 \%$.

Nurses who have a lower level of work experience have a higher level of stress than nurses with a greater experience, in other words, the more workplace experience they have, the lower their stress level is, with only $1 \%$ of nurses with over 10 years of service are experiencing intense stress, $11 \%$ of those with a workplace experience of 5-10 years have an intense level and $20 \%$ of subjects who have less than 5 years of service, have a high level of stress.

According to Table 1, there are differences in the levels of stress related to each of the departments, so the nurses working on the Hematology department have the highest level of stress, followed by the subjects working in the Emergency. On the third place in the ranking of intense stress are the subjects working on the Intensive Therapy. Nurses working in the Pediatrics department have a lower score of intense stress, and as can be seen from the table, nurses working on the Cardiology Department do not have a high stress level, but $80 \%$ of them have a moderate level of stress.

TABLE 1. Level of stress, comparison on different sections

\begin{tabular}{|l|c|c|c|}
\hline Section & $\begin{array}{c}\text { Low } \\
\text { stress }\end{array}$ & $\begin{array}{c}\text { Moderate } \\
\text { stress }\end{array}$ & $\begin{array}{c}\text { Intense } \\
\text { stress }\end{array}$ \\
\hline Cardiology & $20 \%$ & $80 \%$ & $0 \%$ \\
\hline Intensive therapy & $10 \%$ & $50 \%$ & $40 \%$ \\
\hline Hematology & $10 \%$ & $20 \%$ & $70 \%$ \\
\hline Pediatrics & $20 \%$ & $53 \%$ & $27 \%$ \\
\hline Emergency & $13 \%$ & $34 \%$ & $53 \%$ \\
\hline
\end{tabular}

In Fig. 2, the results confirm differences in the level of emotional distress related to the length of time that nurses have at the workplace. Thus, nurses who have more than 10 years of experience have a total distress score of 38-50, nurses with 5-10 years of experience have an emotional distress score of $42-82$, and nurses with less than 5 years of experience have a distress level of 50-89.

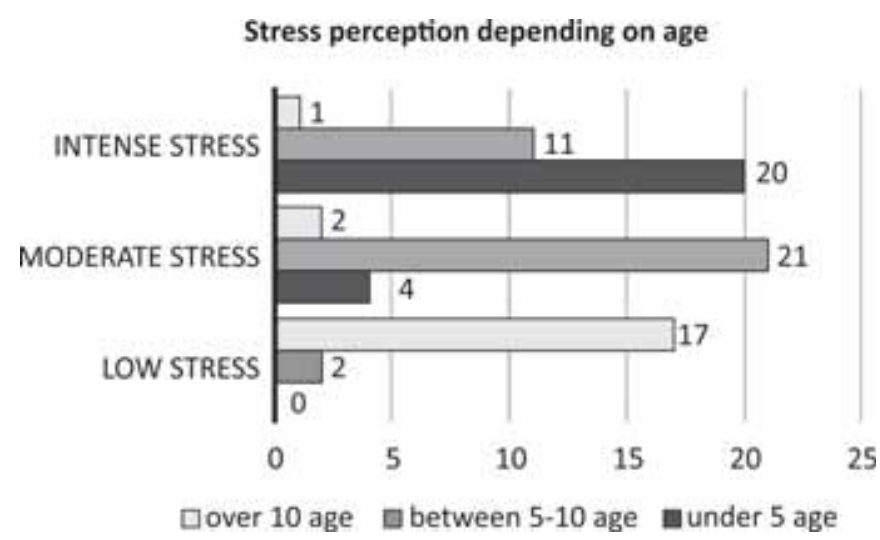

FIGURE 1. Perception of stress by age 
P.D.A. total score by working age

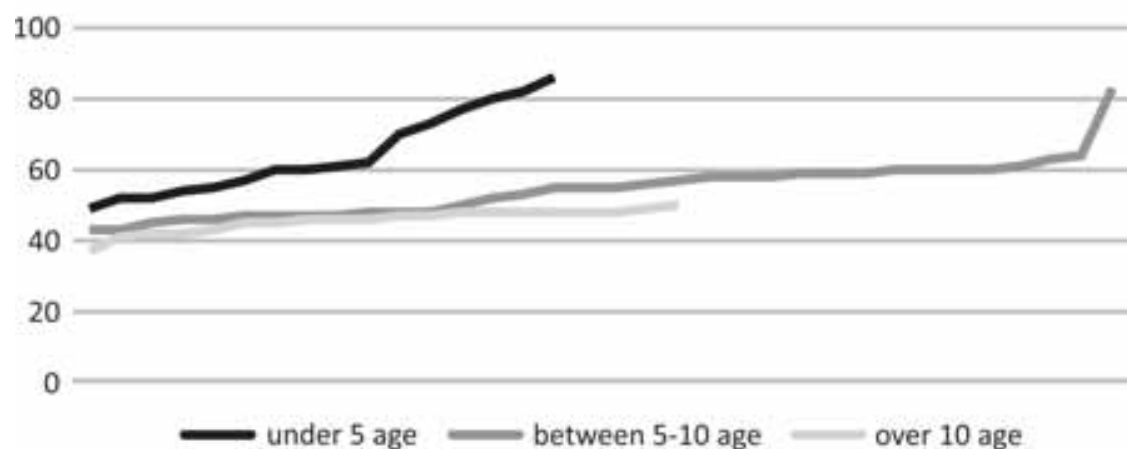

FIGURE 2. Affective distress profile - Total score by working age

Fig. 3 compares the level of emotional distress from nurses working in various hospital departments. As it can be observed, the Department of Pediatrics and the Department of Cardiology have approximately the same moderate level of stress. In the Intensive Care Unit, although apparently the level of emotional distress is low, it increases towards moderate, reaching the limit of intense distress. In the emergency department the level of distress starts moderately, pointing to a level of intense emotional distress. The highest level of emotional distress is encountered in the Hematology section.

\section{DISCUSSIONS}

It is a known fact that nurses are facing high levels of occupational stress. Stress in the nurse's profession has been evaluated in numerous studies using different tools. All these studies reported a high level of stress among nurses in different specialties (9-12).
A study on occupational exhaustion affecting the main categories of healthcare professionals in a hospital, not just doctors or nurses, was made at the University Hospital in Tainan, Taiwan in 2014. It was aimed towards the determination of the frequency and factors that cause burnout on each professional category. A total of 1,329 medical professionals were recruited to participate in the study, and all participants completed an electronic questionnaire daily. The five medical professions included in the study and the number of participants were: physician (101 persons), licensed medical assistant (68 persons), nurse (570 persons), medical technician (216 persons), administrative staff (374 people).

Women had significantly higher scores of personal and professional exhaustion than men. Older staff had significantly lower exhaustion scores than the younger staff on all the three burnout dimensions. Among the medical professions, nurses and licensed nurses had the highest burnout scores (13).

PDA total score in diferent section

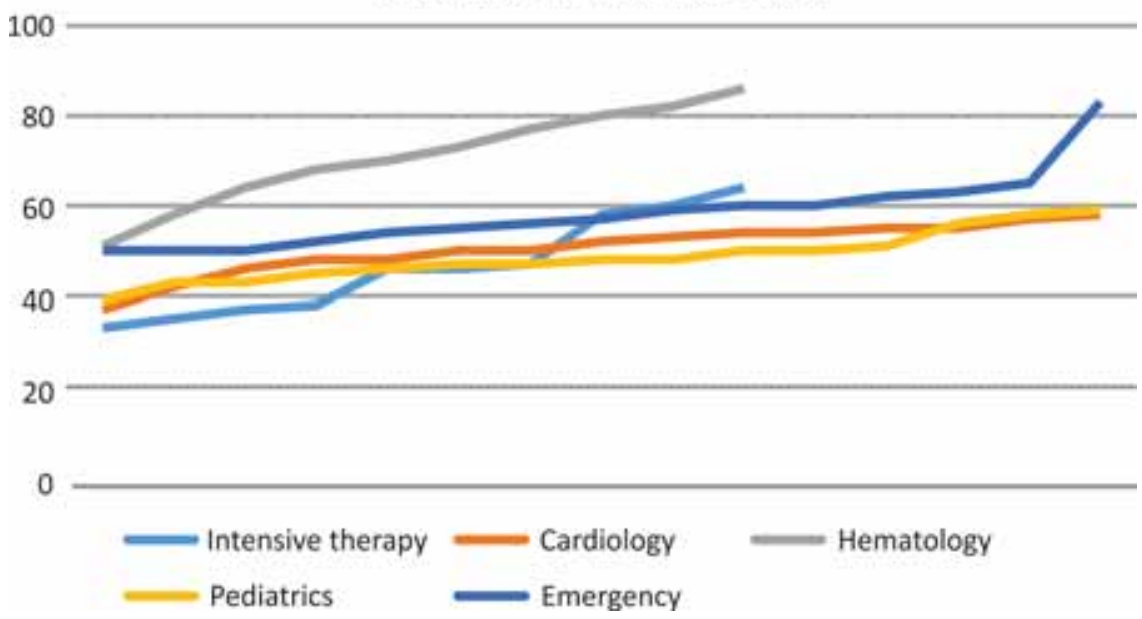

FIGURE 3. Profile of affective distress - Total score by section 
According to a study on the quality of working life of nurses, one third of Romanian nurses work in extreme stress: $30 \%$ of interviewees in the study gave answers that place them in the state of extreme stress, which leads them to the area of burn-out. It is a state of physical and mental exhaustion that can lead to suicide, because that person feels misunderstood.

Another study, carried out on the nurses working on the Intensive Care Unit, reveals that $51 \%$ of the subjects suffer from a high level of stress.

The first major stressors for the nurses involved in the study were: rapid decision-making, the need to carry out unpleasant tasks, and the ownership of high responsibility. For the Emergency Service, one of the reasons for stress is the lack of equipment appropriate to the Emergency system. The lack of personnel and the consequences of this was one of the stress-triggering factors on the Hematology Department. The lack of dedicated teaching programs as well as the lack of protocols for ATI nurses can be responsible for the high impact of stress factors on decision-making and accountability. For the Pediatrics Department, one of the stress-triggering factors was the fragility of a child's life and the responsibility he has in caring for and sustaining this life.

The highest score of emotional distress belongs to subjects working in the Hematology department. They are followed by the Emergency service. The third place is held by the medical assistants in the A.T.I. Department, followed by the Department of Cardiology and Pediatrics, who are having almost the same trajectory of the level of stress on the axis.

\section{CONCLUSIONS}

The present study is useful for medical professionals who work in high stress conditions having in sight the founding of prevention measures, as well as finding methods of fighting the stress.

\section{REFERENCES}

1. Vela-Bueno A., Moreno-Jiménez B., Rodríguez-Muño A., OlavarrietaBernardino S., Fernández-Mendoza J., De la Cruz-Troca J.J., Vgontzas A.N. (2008). Insomnia and sleep quality among primary care physicians with low and high burnout levels. Journal of Psychosomatic Research, 64:435-442;

2. Adam S., Gyoffy Z., Susanszky E. (2008). Physician Burnout in Hungary: A potential Role for Work Family Conflict. J Health Psychol, 13:847-856;

3. Davey M.M., Cummings G., Newburn-Cook C.V., Lo E.A. (2009). Predictors of nurse absenteeism in hospitals: A systematic review. Journal of Nursing Management, 17, 312-330;

4. Escribá-Agüir V., Martin-Baena D., S. Pères-Hoyos (2006). Psychosocial work environment and burnout among emergency medical and nursing staff. Int Arch Occup Environ Health, 80:127-133;

5. Freudenberger H.J. (1974). Staff burnout. Journal of Social Issues, 30(1), 159-165;

6. Leiter M.P., Maslach C. (2009). Nurse turnover: The mediating role of burnout. Journal of Nursing Management, 17, 331-339;

7. World Health Organization (2009). The European Health Report. Health and health systems.

8. Opriş D., Macavei B. The profile of emotional distress; norms for the Romanian population. Journal of Cognitive and Behavioral Psychotherapies, 8, 139-158. 2007

9. Hogea L., Hogea B., Bredicean C.A., Chiriac D. (2016). Prevalence of the
Burnout Syndrome Among Medical Staff. Fiziologia, Timisoara, nr. 4 (13).

10. Henderson V. (1978). The concept of nursing. Journal of Advanced Nursing, 3, 113-130.

11. Lazarus R.S. (2006). Emotions and Interpersonal Relationships: Toward a Person Centered Conceptualization of Emotions and Coping, Journal of Personality, 74, 1, 9-46.

12. Stress at work (1999). United States National Institute of Occupational Safety and Health, Cincinnati.

13. Vagg P.R., Spielberger C.D. (1998) Occupational stress: Measuring job pressure and organizational support in the workplace. J Occup Health Psychol. 3(4):294-305. 